\title{
Multiple Pigmented Conjunctival Lesions following Intravitreal Injections in a Patient with Uveal Melanoma
}

\author{
Niels J. Brouwer ${ }^{a}$ Gregorius P.M. Luyten ${ }^{a}$ Sjoerd G. van Duinen ${ }^{b}$ \\ Martine J. Jager ${ }^{\text {a }}$ Marina Marinkovic ${ }^{\text {a }}$ \\ Departments of a Ophthalmology and ${ }^{b}$ Pathology, Leiden University Medical Centre, Leiden, The Netherlands
}

\section{Keywords}

Uveal melanoma · Pigment · Intravitreal injection ·

Brachytherapy

\begin{abstract}
Purpose: This paper reports a case of pigmented conjunctival lesions after intravitreal injections in a patient who received brachytherapy for uveal melanoma. Methods: Clinical and histopathological examination of the pigmented conjunctival lesions was performed. Results: A 57-year-old male who was treated with brachytherapy for uveal melanoma developed radiation retinopathy. Following intravitreal anti-vascular endothelial growth factor (VEGF) injections, 2 pigmented conjunctival spots appeared at the injection sites. After excision of the lesions, histopathology showed pigment-loaded macrophages, with no signs of active tumour cells. Conclusion: Two conjunctival lesions that appeared following uveal melanoma brachytherapy and anti-VEGF injections were excised under suspicion of tumour seeding. Histopathology, however, showed aggregates of pigment-loaded macrophages.

(c) 2016 S. Karger AG, Basel
\end{abstract}

๑) 2016 S. Karger AG, Basel

E-Mail karger@karger.com

www.karger.com/oop

\section{Introduction}

Uveal melanoma is the most common intraocular tumour in adults with an incidence rate of 5.1 per million in Caucasians [1]. Various treatment modalities are available, including brachytherapy, proton beam irradiation, and enucleation $[2,3]$. Plaque therapy with Ruthenium 106 provides excellent tumour control, but local recurrence or extraocular outgrowth may occur in rare cases [4]. Patients may develop radiation retinopathy with macular edema as a complication requiring treatment with vascular endothelial growth factor (VEGF) inhibitors or corticosteroids $[3,5]$. We describe a patient who was treated with brachytherapy for uveal melanoma and who developed radiation retinopathy for which he was treated with intravitreal injections. Subsequently, he developed pigmented lesions at the injection sites.

\section{Case Report}

A 57-year-old, white, Caucasian male was referred with decreased visual acuity and a lesion suspicious for malignancy. On fundus examination, there was a juxtapapillary choroidal tumour with an intravitreal haemorrhage. Ultrasonography showed a cho-

Dr. Marina Marinkovic

Department of Ophthalmology LUMC, PO Box 9600

NL-2300 RC Leiden (The Netherlands)

E-Mail m.marinkovic@lumc.nl 


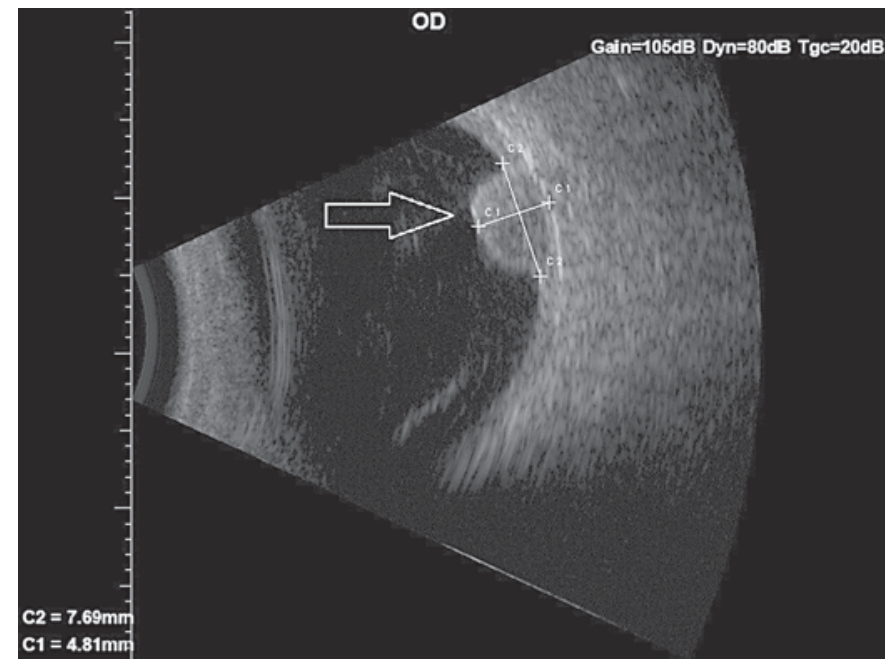

Fig. 1. Ultrasound image showing the dome-shaped choroidal melanoma before brachytherapy (arrow).
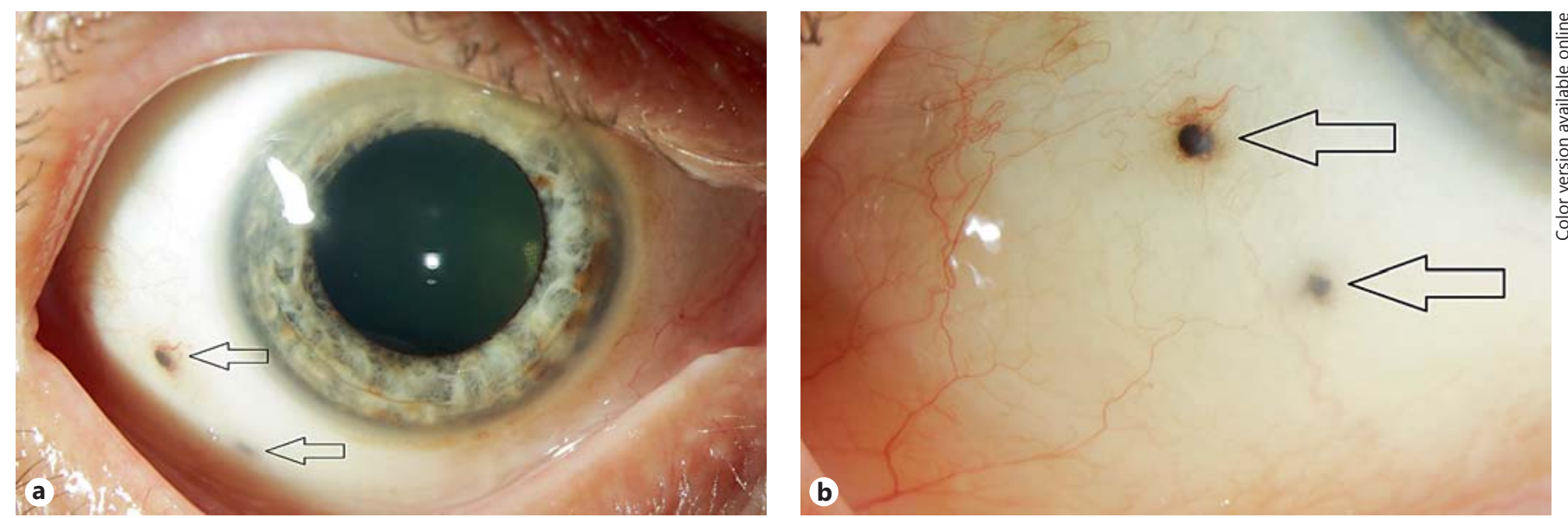

Fig. 3. Conjunctival lesions. a Pigmented lesions on the conjunctiva, located at 7 and 8 o'clock (arrows). Some melanosis is visible at the limbus, unrelated to the pigmented lesions. b Magnification of the lesions (arrows). Near the upper lesion, some small conjunctival vessels are visible, while near the lower lesion no vessels are seen.

roidal tumour measuring $9.3 \times 7.7 \mathrm{~mm}$ in basal diameter and 5.2 $\mathrm{mm}$ in tumour thickness without retinal invasion or breakthrough of Bruch's membrane (Fig. 1). The clinical examination was consistent with the diagnosis of choroidal melanoma. Ruthenium plaque brachytherapy was performed with a COB applicator 20 $\mathrm{mm}$ in diameter, designed for administering radiation on the posterior pole adjacent to the optic nerve (BEBIG GmbH, Berlin, Germany), and the tumour flattened gradually to $4.6 \mathrm{~mm}$ after 3 years (Fig. 2). Seventeen months after brachytherapy, the visual acuity in the treated eye decreased from $0.7(20 / 29)$ to $0.4(20 / 50)$ due to macular edema caused by radiation retinopathy. The patient was treated with a series of 3 intravitreal anti-VEGF injections with

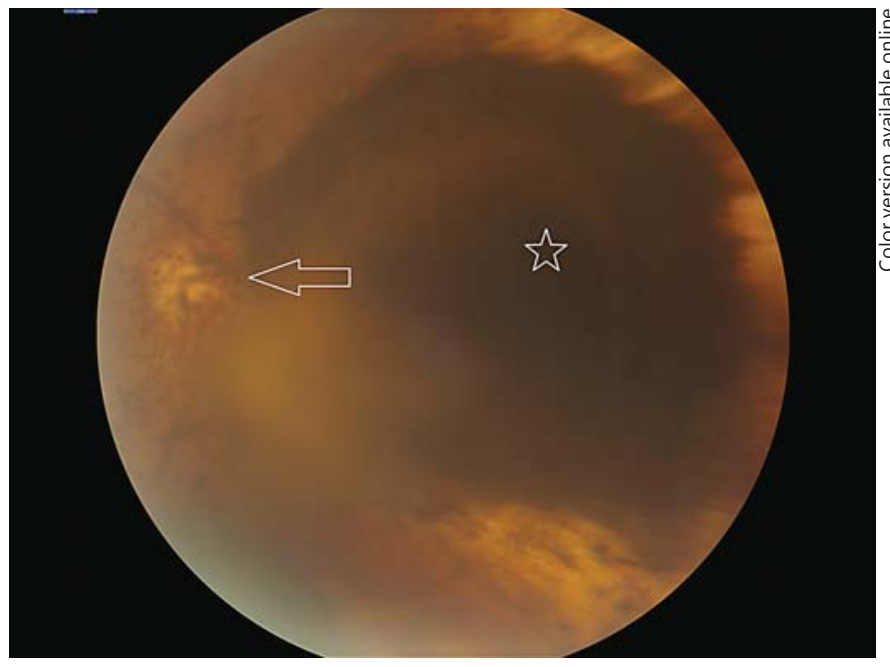

Fig. 2. Fundoscopic image of the pigmented tumour (star) adjacent to the optic disc (arrow) with floating pigmented cells most readily visible in the front of the optic disk after brachytherapy. bevacizumab $(1.25 \mathrm{mg}=0.05 \mathrm{~mL})$ in 4 -week intervals, followed by a series of 3 intravitreal injections with ranibizumab $(0.5 \mathrm{mg}=0.05$ $\mathrm{mL}$ ) in four-week intervals due to lacking response. All injections were administered in the temporal-inferior quadrant at $4 \mathrm{~mm}$ distance from the limbus, with a regular $30 \mathrm{G}$ needle. Six months after the first injection, 2 pigmented lesions appeared on the bulbar conjunctiva, raising suspicion of tumour cell seeding (Fig. 3). Both lesions were located at the exact sites of the anti-VEGF injections, opposing the location of the tumour, and not at perforating vessel locations. As a needle track-related outgrowth of malignancy was suspected, an excisional biopsy was performed. The lesions were excised with large margins, leaving the inner sclera intact without 

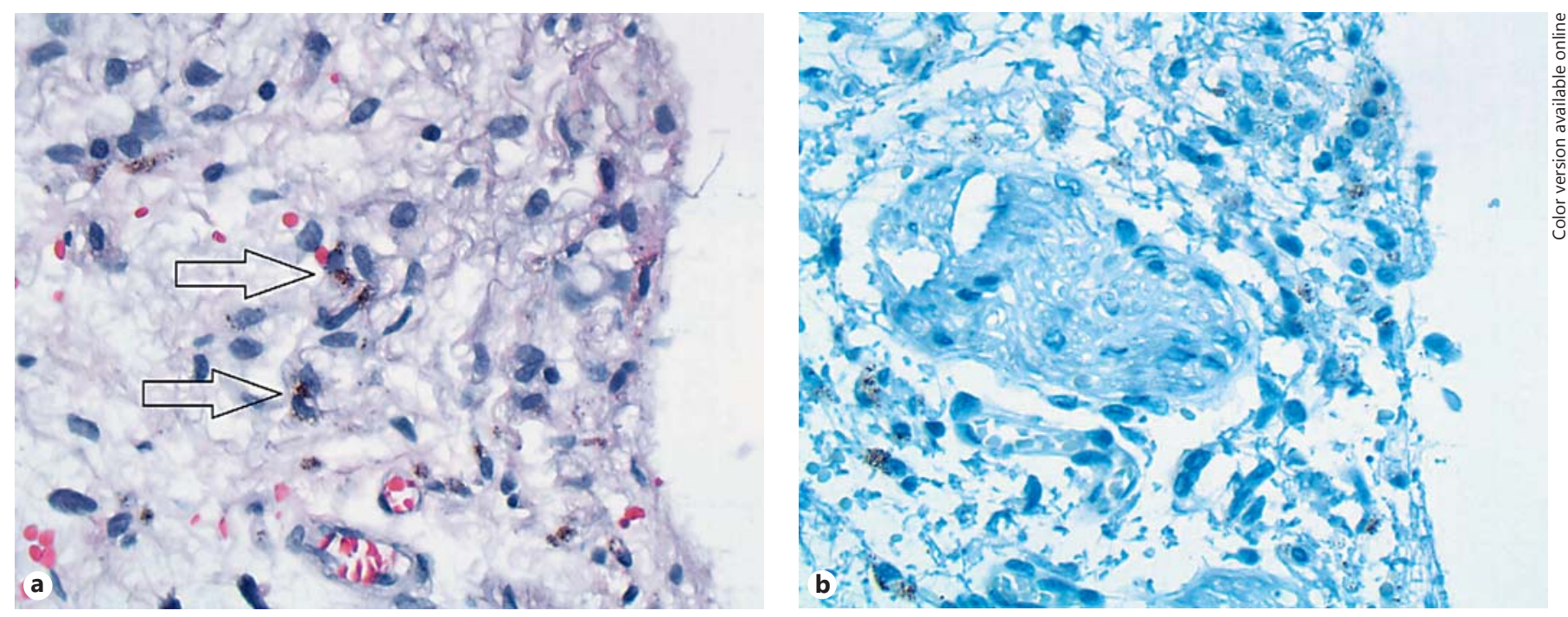

Fig. 4. Histopathology. a Histology of the pigmented lesion showing conjunctival stroma with scattered cells with brown cytoplasmic pigment and small nuclei (arrows). HE stain. Original magnification, $\times 40$. b The cells are not reactive for Melan-A. In some cells, brown pigmentation persisted despite melanin depigmentation, but it is very distinct from the immunohistochemical reaction product. Melan-A stain after melanin depigmentation. Original magnification, $\times 40$. $c$ The cells show positive staining for macrophage-specific CD68. CD68 staining after melanin depigmentation. Original magnification, $\times 40$.

any macroscopically visible pigmentation. Histopathological examination demonstrated the presence of cells in the conjunctival stroma with small nuclei and cytoplasmic melanin pigment (Fig. 4). Staining with anti-CD68 showed that the majority of these cells were macrophages, whereas a melanocytic origin of the cells could not be demonstrated by Melan-A staining. No additional treatment was given, and no recurrences have been observed within the 3 months following excision.

\section{Discussion}

The occurrence of pigmented conjunctival lesions following uveal melanoma treatment or needle insertion has been described, which includes cases of tumour seeding following fine-needle aspiration biopsy (FNAB) or open 
ment were administered in a patient with uveal melanoma. To our knowledge, no other cases of pigmented lesions following this procedure have been described. Histopathology showed that the pigmentation was most probably caused by melanin-loaded macrophages. We therefore suggest that the mechanism of pigmentation in our case occurred due to migration of pigment-loaded macrophages to the injection site of the intravitreal injection, reaching the deep conjunctival layers. Alternatively, the brachytherapy-induced tumour cell necrosis must have led to the presence of numerous melanin-containing macrophages in the vitreous that may have adhered to the needle.

Summarizing our case, this is the first known report of a pigmented conjunctival lesion at the injection site of intravitreal treatment for radiation retinopathy following brachytherapy for uveal melanoma. Ophthalmologists should be aware that new conjunctival pigmented lesions in patients with uveal melanoma are not necessarily malignant.

\section{Statement of Ethics}

Written informed consent was obtained from the patient for this report.

\section{Disclosure Statement} close.

The authors state that they have no conflicts of interest to dis-

\section{References}

1 Singh AD, Turell ME, Topham AK: Uveal melanoma: trends in incidence, treatment and survival. Ophthalmology 2011;118:18811885.

2 Jager MJ, Desjardins L, Kivelä T, Damato BE (eds): Current Concepts in Uveal Melanoma. Dev Ophthalmol. Basel, Karger, 2012, vol 49, pp 16-26.

3 Tarmann L, Wackernagel W, Avian A, Mayer C, Schneider M, Winkler P, Langmann G: Ruthenium-106 plaque brachytherapy for uveal melanoma. Br J Ophthalmol 2015;99:16441649.
4 Damato B, Patel I, Campbell IR, Mayles HM, Douglas Errington R: Local tumor control after 106Ru brachytherapy of choroidal melanoma. Int J Rad Oncol Biol Phys 2005;63: 2:385-391.

5 Wen JC, McCannel TA: Treatment of radiation retinopathy following plaque brachytherapy for choroidal melanoma. Curr Opin Ophthalmol 2009;20:200-204.

6 Caminal JM, Sanz S, Carreras M, Catala A, Arruga J, Roca G: Epibulbar seeding at the site of a transvitreal fine-needle aspiration biopsy. Arch Ophthalmol 2006;124:587-588.
7 Schefler AC, Glolgorsky D, Marr BP, Shields CL, Zeolite I, Abramson DH: Extraocular extension of uveal melanoma after fine-needle aspiration, vitrectomy and open biopsy. JAMA Ophthalmol 2013;131:1220-1224.

8 Mashayekhi A, Lim RP, Shields CL, Eagle RC, Shields JA: Extraocular extension of ciliochoroidal melanoma after transscleral fine-needle aspiration biopsy. Retin Cases Brief Rep 2016;10:289-292.

9 Toivonen P, Kivela T: Pigmented episcleral deposits after brachytherapy of uveal melanoma. Ophthalmology 2006;113:865-873. 